\title{
ANNUITIZATION BEHAVIOR: TAX INCENTIVES VS. PRODUCT DESIGN
}

BY

AlEXANDER Kling, ANDREAs Richter AND JOCHEN Ruß

\begin{abstract}
We analyze and compare the impact of tax incentives and of introducing enhanced annuities on annuitization behavior considering heterogeneity among the insured. We find that tax incentives for annuitization result in a significant increase of the portion of people who should annuitize and also an increase of the insurer's profit since less healthy individuals also annuitize, i.e. adverse selection is reduced. However, the problem that different insured receive a different value for money is even increased by tax incentives. If enhanced annuities are introduced, the percentage of insured who should annuitize further increases. Adverse selection is further reduced and the differences in value for money from annuitizing shrink.
\end{abstract}

\section{KEYWORDS}

Tax incentives, enhanced annuities, optimal annuitization.

\section{INTRODUCTION}

In many countries tax incentives exist for annuitizing benefits from an old age provision contract. In Germany, for instance, since 2005 a strong tax incentive has been introduced for annuitizing money that has been accumulated within an insurance contract: if the benefit from an insurance contract is received as a lump sum, then - depending on certain criteria - either $50 \%$ or $100 \%$ of the difference between the lump sum benefits received and premiums paid (that is, the capital gain) have to be taxed. If, however, the benefit is converted into a lifelong annuity, then only the so-called taxable portion of each annuity is taxed. The taxable portion is given in the German income tax law and depends only on the insured's age when the annuity payments start. For instance if the annuity payments start at age 65 , then $18 \%$ of each annuity payment has to be taxed at the beneficiary's individual income tax rate (the table of taxable portions is given in Appendix A). This taxable portion is a rather rough and simplified approximation for the earnings after the annuity payments start, assuming, e.g., 
that a fixed rate of interest of 3\% is earned each year and that everybody lives exactly to their life expectancy (cf. e.g. Richter and Ruß, 2002). ${ }^{1}$ For immediate annuities, this means that taxes are paid on an approximation for the earnings received from the policy. For deferred annuities, however, this means that essentially all earnings from the accumulation phase are tax-free if the contract is annuitized and only earnings after the start of the annuity phase are taxed. Similar tax privileges for annuitization hold in many other countries, as well.

There are, of course, several reasons why the government may choose to provide tax incentives for annuitization. Primarily, such incentives are implemented in order to encourage individuals to hedge against the risk of outliving their money. Particularly at times where in many countries benefits from state funded (pay-as-you-go) pension systems are being reduced, these incentives seem to be necessary in order to stimulate demand. Whereas empirical studies seem to confirm that the money's worth of an annuity in many situations is typically high enough to make purchasing this product attractive for an individual (see, e.g. Mitchell et al., 1999; James and Song, 2001), real world markets so far show surprisingly little demand for annuities. Reasons for this, as discussed in the literature, include adverse selection (see for instance Finkelstein and Poterba, 2004), bequest motives (see e.g. Bernheim, 1991), precautionary savings for compensating income risk by factors such as health problems (see Strawczynski, 1999), and inner-family risk-sharing (Kotlikoff and Spivak, 1981).

Whilst tax Incentives can stimulate demand for annuities, they can also create undesired effects in markets where only standard annuities (and no substandard annuities, such as enhanced or impaired annuities ${ }^{2}$ ) exist. In standard annuities, annuity providers use average mortality rates to determine the annuity that will be paid out for a given premium. Thus, the ratio of invested premium and lifelong annuity depends only on age and gender but not on the individual health condition of the insured. Therefore, an annuity contract that may be priced at an actuarially fair rate for an average individual may be rather unattractive for a person with certain medical impairments and rather attractive for a very healthy person. As a consequence, such standard annuities provide a good value for money only for people with at or above average life expectancy. With enhanced or impaired annuities, insurers attempt to offer the same value for money to all clients: At the start of the contract for immediate annuities or at the end of the accumulation period for deferred annuities, the condition of the insured is assessed e.g. by some form of individual underwriting. The underwriting results are converted into individual mortality probabilities that are then used for pricing the annuity contract. Thus, the resulting annuity payment is the higher, the shorter the life insurer's estimate for the insured's life expectancy.

In the absence of both, tax incentives for annuitization and enhanced annuities, the majority of people with below average life expectancy would choose not to annuitize their contract at the end of the deferment period. This is also consistent with two observations made in many insurance markets: Observed annuitization rates are rather low and people who do annuitize have significantly lower mortality rates than people who don't annuitize. 
In the presence of enhanced annuities, at least in theory (i.e. if the underwriting is assumed to be "perfect"), everybody should receive the same value for money when taking out an annuity. The decision whether or not to annuitize should then be independent of the insured's health. Tax incentives for annuitization in a market with enhanced annuities should therefore significantly increase the acceptance of annuities - for healthy as well as impaired.

If, however, tax incentives for annuitization do exist in a market where enhanced annuities are not being offered, then essentially a person with certain medical impairments at the end of the accumulation period faces the following dilemma: The insured can either receive a lump sum benefit which is not tax efficient or annuitize the money which is tax efficient but comes at too high a price given the individual state of health. In other words, a portion of the tax benefit is implicitly taken away from an impaired person due to the poor value for money of the annuity contract.

This paper analyzes the financial consequences of this situation from the perspective of both, the insured and the insurer and explores how the presence of impaired annuities changes these consequences. We perform quantitative analyses under the current German taxation rules but want to stress that the qualitative results should be similar in all markets with tax incentives for annuitization.

The remainder of this paper is organized as follows: In Section 2, we present our model framework. In particular, we will specify heterogeneity among the insured through a simple frailty model for the individual's mortality. In this model, a so called frailty factor describes the individual's state of health. We also introduce our model for underwriting, i.e. how the estimated frailty factor (that is the result of the underwriting process) relates to the actual frailty factor of an individual. Furthermore, we introduce the considered annuity products: a standard annuity that does not depend on the individual's state of health and an enhanced annuity where this information is considered in the pricing. Finally, we explain the considered tax regimes: the so-called "old" tax regime without incentives for annuitization and the "new" tax regime, where such incentives have been introduced.

In Section 3, we analyze - in a market where only standard annuities exist under what circumstances annuitization is preferable from an individual's point of view depending on age, tax rate and the individual's state of health. We introduce the so-called critical frailty factor: If the insured's individual frailty factor is below the critical frailty factor, then annuitization is preferable. We analyze for risk neutral and risk adverse individuals how the critical frailty factor depends on age and tax rate and in particular how introducing tax incentives for annuitization affects critical frailty factors.

In Section 4, we extend our analyses to a pool of individuals that is heterogeneous with respect to mortality. We explore how the portion of individuals who should annuitize changes as we move from the old to the new tax regime. We also analyze the effect on the insurer's profitability. Since one finding is that the heterogeneity of the value for money amongst the pool of insured increases due to the tax incentives, we finally analyze in Section 5 the effects of 
introducing enhanced annuities. We find that in a market with enhanced annuities three positive effects occur: The portion of people who should annuitize increases, adverse selection is reduced, and the heterogeneity of the value for money within the pool of insured decreases.

\section{THE MODEL FRAMEWORK}

The following analyses require the use of different types of mortality rates: Mortality rates used by the insurer to price standard annuities, mortality rates used by the insurer to price enhanced annuities, and the actual mortality rates of the individual given his state of health. The latter rates are of course unknown to the insurer. For all analyses throughout this paper, we use the German mortality table DAV 2004R (for males) issued by the German Actuarial Association (Deutsche Aktuarvereinigung, DAV) as a basis and refer to this table as the standard table.

\subsection{Heterogeneity of mortality}

A central aspect of our model is that we consider heterogeneity with respect to mortality, i.e. we allow for different individuals of the same age and gender to have different mortality rates and hence different life expectancies. To specify this heterogeneity we use a simple frailty model for the individual mortality (cf. e.g. Vaupel et al., 1979): each person is characterized by a so-called frailty factor or mortality multiplier $d$. This person's individual mortality probabilities are then given by $d$ times the mortality probabilities from the standard table. A person with $d>1(\mathrm{~d}<1$ respectively) has above average (below average) mortality and thus below average (above average) life expectancy. ${ }^{3}$

For our analyses in Section 3, we look at an individual insured. There, we analyze the impact of the frailty factor on the optimal decision to annuitize in a model with and without tax incentives for annuitization. In Section 4, however, in order to quantify the impact on an insurer, we look at a pool of persons with different frailty factors. There, we need to specify the distribution of frailty factors among the population. Vaupel et al. (1979) propose that the frailty factor $d$ in the general population should follow a Gamma distribution. Further, Hoermann and Ruß (2008) demand that the distribution is continuous, making possible very fine nuances in state of health and remaining life expectancy; that its domain is positive; that the probability density function is "flat" at zero and equal to zero for $d=0$, since mortality rates near zero are unrealistic; that the distribution is right-skewed, i.e., very high values of $d$ can occur; and that the expected value $\mathrm{E}(d)=1,{ }^{4}$ i.e., the standard mortality table describes an "average individual. They further state that mortality rates close to zero are unrealistic because certain accidents are inevitable. Based on these arguments, they propose to use a (translated) gamma-distribution $D$ with density function $f_{(\alpha, \beta, \gamma)}^{\Gamma}(d)=\frac{1}{\Gamma(\alpha) \beta^{\alpha}}(d-\gamma)^{\alpha-1} e^{\frac{-(d-\gamma)}{\beta}}$ for $d \geq \gamma, \gamma \in I R, \alpha, \beta>0$, expected 


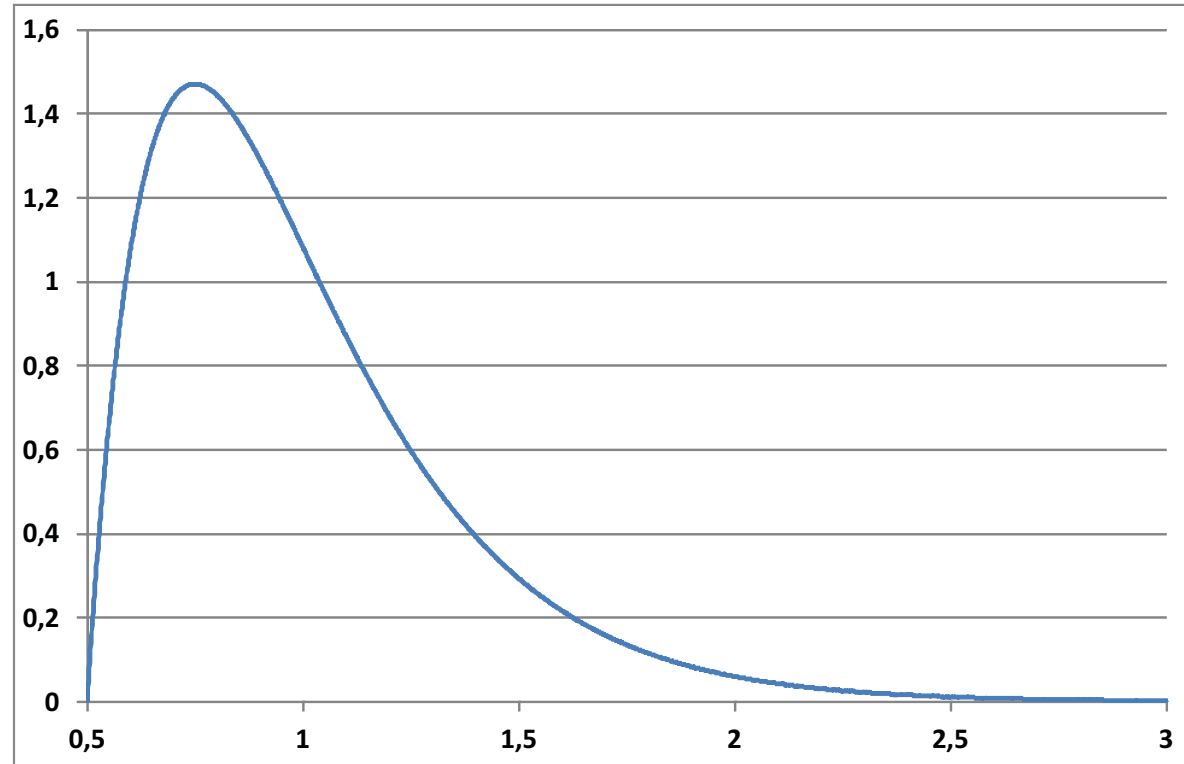

FIGURE 1: Density function of the translated gamma distribution with parameters $\alpha=2, \beta=0.25$ and $\gamma=0.5$. (Color online)

value $\alpha \beta+\gamma$, variance $\alpha \beta^{2}$ and parameters $\alpha=2, \beta=0.25$ and $\gamma=0.5$. In our analyses, we will also use this distribution. The density function is displayed in Figure 1.

\subsection{The insurance contracts}

For our analyses, we consider a standard annuity and an enhanced annuity product. We assume a lifelong fixed annuity without death benefit and without profit participation. We also disregard any charges. We assume that, as usually done in practice, for pricing the annuity, the insurer uses some mortality table and some technical interest rate.

2.2.1. The standard annuity. In the case of the standard annuity, for a given premium $P$ (that can either be a single premium paid into an immediate annuity or some amount accumulated during the accumulation phase of a deferred annuity), the lifelong annuity paid to the client is given by $\frac{P}{\ddot{a}_{x}}$, where

- $\ddot{a}_{x}=\sum_{k=0}^{\omega-x}{ }_{k} p_{x} \cdot v^{k}$ denotes the present value of an immediate annuity paying 1 unit of currency annually in advance,

- ${ }_{k} p_{x}=\prod_{i=1}^{k}\left(1-q_{x+i-1}\right)$ is the probability of an $x$-year old male to survive for another $k$ years, 
- $q_{x}$ denotes the probability that an average $x$-year old male dies within the next year,

- $r$ denotes the pricing discount rate, and

- $v=\frac{1}{1+r}$.

We assume that all these probabilities are taken from the standard table.

2.2.2. The enhanced annuity. The enhanced annuity is calculated analogously, with only one difference: In pricing the annuity, the survival probabilities are substituted by probabilities resulting from some individual underwriting. For individual underwriting, we follow an approach also proposed by Hoermann and $\mathrm{Ru} B$ (2008): We assume that the process of individual underwriting assigns each insured an estimate $\hat{d}$ of the insured's actual (unknown) frailty factor $d$. We model the result of the underwriting as a realization of a random variable $\hat{D}$ and assume $D$ and $\hat{D}$ to be identically distributed. This means that there is no systematic underwriting error, i.e., the mortality estimation of the underwriting across the whole population is not only correct on average but also with respect to the portion of people identified as belonging to a certain impairment range. ${ }^{5}$ Furthermore - because we wish to focus on the pure effect of introducing individual underwriting - we do not consider any safety loadings that could, however, easily be incorporated in the model.

We assume the random variables $D$ and $\hat{D}$ to be correlated with a correlation coefficient $0 \leq \rho_{D, \hat{D}} \leq 1$. This correlation coefficient determines the quality of the individual underwriting: the larger $\rho_{D, \hat{D}}$, the smaller the mean deviation between $d$ and $\hat{d}$. For a correlation of 1 , we are in the case of "perfect underwriting", where the underwriting process assigns the correct frailty factor to each individual.

Thus, for the enhanced annuity product, the annuity amounts to $\frac{P}{\hat{\hat{a}}_{x}}$, where $\hat{\vec{a}}_{x}=\sum_{k=0}^{\omega-x} k \hat{p}_{x} \cdot v^{k}$. Here, ${ }_{k} \hat{p}_{x}=\prod_{i=1}^{k}\left(1-\hat{d}^{*} q_{x+i-1}\right)$ is the probability of an $x$-year old male to survive for another $k$ years applying the mortality probabilities resulting from the individual underwriting. ${ }^{6}$ To calculate these mortality probabilities, the estimated frailty factor $\hat{d}$ is applied to the standard table.

\subsection{The considered tax regimes}

As mentioned above, Germany changed the taxation of life insurance benefits in 2005 and introduced strong tax incentives for annuitizing money that has been accumulated within an insurance contract. We use the situation in Germany before 2005 as our model environment without tax incentives and the situation in Germany since 2005 as our model environment with tax incentives for annuitization.

The situation before 2005 was very simple. Under certain conditions (most importantly a minimum term to maturity of 12 years), lump sum benefits from insurance contracts were tax free. If the benefit was annuitized, then the socalled taxable portion explained in Section 1 of each annuity payment was taxed 
at the beneficiary's individual income tax rate. Since this taxable portion is an approximation for the earnings after the annuity payout starts, essentially in case of annuitization also all earnings from the accumulation period were tax free. As a consequence, the taxation of earnings during the accumulation phase was the same whether or not the client did annuitize.

The situation since 2005 is as follows: For lump sum benefits, under certain conditions (most importantly a minimum term to maturity of 12 years and a minimum age of the beneficiary), $50 \%$ of the difference between benefits received and premiums paid are taxed at the beneficiary's individual income tax rate. If the conditions are not fulfilled, then $100 \%$ of this difference is taxed at a flat tax rate of $25 \%$. If the benefit is annuitized, the annuity is still taxed with the taxable portion. As a consequence, essentially all earnings from the accumulation period are tax free if the money is annuitized but at least $50 \%$ of these earnings are taxable if the money is taken as a lump sum. This is a rather strong tax incentive for annuitization, in particular if a contract had significant earnings in the accumulation phase.

In all analyses that follow in the next Sections, we assume that the relevant criteria to qualify for the lower taxation of lump sum benefits are fulfilled.

\section{ANALYSES FROM AN INDIVIDUAL'S PERSPECTIVE}

In this Section, we analyze the effect of tax incentives for annuitization on an individual in a market without enhanced annuities, i.e. the insurer has no information about the insured's state of health and prices the annuity according to the formula given in section 2.2.1.

We assume that an individual has accumulated a certain amount of money $P$ during the accumulation phase of an insurance contract and now has to choose between receiving this amount $P$ as a lump sum benefit and annuitizing in a standard annuity amounting to $\frac{P}{\ddot{a}_{x}}$ independent of the insured's health status.

Therefore, the (ex ante expected) value of the annuity payments is higher for a healthy and lower for an impaired insured. In particular, for an insured aged $x$ with a certain frailty factor $d(x)$ and a marginal tax rate $\tau$, the present value of the expected stream of annuity payments after taxes is given by

$$
\sum_{k=0}^{\omega-x} \frac{P}{\ddot{a}_{x}}(1-t(x) \cdot \tau) \cdot{ }_{k} \tilde{p}_{x}\left(\frac{1}{1+r *}\right)^{k},
$$

where ${ }_{k} \tilde{p}_{x}=\prod_{i=1}^{k}\left(1-d(x) \cdot q_{x+i-1}\right)$ is the survival probability considering the insured's actual frailty factor, $t(x)$ denotes the taxable portion of the annuity (that depends only on the age of the insured when the annuity starts, see Appendix A), and $r^{*}$ denotes the discount rate (which need not coincide with the insurer's pricing discount rate $r$ ). 
This present value of the annuity (after tax) is the same under both the old and the new tax regimes. If the client does not annuitize, the lump sum benefit before taxes is of course $P$. Under the old tax regime without tax incentives for annuitization, the lump sum benefit after taxes is also $P$ (since the benefit was paid out tax free). Under the new tax regime, the lump sum benefit after taxes is $P-0.5 \cdot(P-p) \cdot \tau$, where $p$ denotes the sum of premiums paid into the insurance contract (since $50 \%$ of the difference between the benefit and the premiums paid is taxed).

We now compare the lump sum benefit after taxes with the present value of the expected annuity after taxes and calculate the so-called critical frailty factor $d^{*}(x)$. This is the factor below which the present value of the expected stream of annuity payments after taxes exceeds the lump sum benefit after taxes, i.e. the value of $d(x)$ for which the equilibrium condition

$$
\sum_{k=0}^{\omega-x} \frac{P}{\ddot{a}_{x}}(1-t(x) \tau) \frac{k \tilde{p}_{x}(d(x))}{\left(1+r^{*}\right)^{k}}=\left\{\begin{array}{cc}
P & \text { "old" tax regime } \\
\left(P-\frac{1}{2}(P-p) \tau\right) \text { "new" tax regime }
\end{array}\right.
$$

holds.

Under the old tax regime, the above equilibrium condition simplifies to

$$
(1-t(x) \tau) \sum_{k=0}^{\omega-x} \frac{\prod_{i=1}^{k}\left(1-d^{*}(x) q_{x+i-1}\right)}{\left(1+r^{*}\right)^{k}}=\sum_{k=0}^{\omega-x} \frac{\prod_{i=1}^{k}\left(1-q_{x+i-1}\right)}{(1+r)^{k}} .
$$

Thus, the critical frailty factor depends only on the age of the insured and the marginal tax rate. In our numerical analyses, we use $r=4 \%$ as a pricing discount rate and $r^{*}=0.75 \cdot r=3 \%$ for calculating the present values since - due to a flat rate taxation of $25 \%$ on interest earnings outside insurance contracts prevailing in Germany - this would be the after tax return if the insured decided to take the lump sum and invest it outside the insurance contract at $r=4 \%$.

Of course, calculating the critical frailty factor in the way introduced above - defined as the level where the money's worth of the annuity equals one, i.e. coincides with the lump sum benefit - implicitly assumes that the insured is risk neutral. However, empirical analysis shows (see Mitchell et al., 1999) that insured decide to annuitize even when the money's worth is significantly below one. This phenomenon can most easily be explained via risk aversion, which generally is considered the most important motive for an individual's insurance demand.

In this spirit, we now additionally introduce a modification in that we assume that individuals even annuitize at a money's worth of 0.9 , and 0.75 , respectively, considering the fact that Mitchell et al. argue that values down to 0.75 would still be consistent with standard utility functions.

Although we do not explicitly model risk aversion, we will refer to these modifications as cases with moderately risk averse annuitants (0.9) and strongly risk averse annuitants $(0.75)$. 
Therefore, we also calculated the critical frailty factors for insured with risk aversion assuming that for the benefit of "hedging against the risk to outlive their money", they would annuitize if the expected present value of the annuity cash-flow exceeds $90 \%$ (or $75 \%$ ) of the corresponding lump sum benefit.

Under the new tax regime, the above equilibrium condition simplifies to

$$
\begin{aligned}
(1-t(x) \tau) \sum_{k=0}^{\omega-x} \frac{\prod_{i=1}^{k}\left(1-d^{*}(x) q_{x+i-1}\right)}{\left(1+r^{*}\right)^{k}}= & \left(1-\frac{1}{2}\left(1-\frac{p}{P}\right) \tau\right) \\
& \times \sum_{k=0}^{\omega-x} \frac{\prod_{i=1}^{k}\left(1-q_{x+i-1}\right)}{(1+r)^{k}} .
\end{aligned}
$$

Thus, the critical frailty factor additionally depends on the ratio $\frac{p}{p}$, i.e. the amount of premiums paid in the accumulation period $p$ divided by the lump sum benefit $P$. The reason is that in the case of a lump sum benefit, taxes have to be paid on $50 \%$ of the earnings in the accumulation phase, i.e. on $0.5 \cdot(P-p)$, whereas alternatively the full amount before taxes $P$ can be annuitized. Note that in practice, the insured typically has a variety of investment choices during the accumulation phase and hence the premiums could earn an arbitrary return leading to arbitrary ratios $\frac{p}{P}$.

From the equilibrium condition, one can e.g. deduce that $d^{*}(x)$ has to exceed 1 for $t(x)<\frac{1}{2}\left(\left(1-\frac{p}{P}\right) \tau\right)$ since $r^{*}<r$ and hence the denominator of the left hand side is lower than denominator of the right hand side. However, exact values of $d^{*}(x)$ as well as dependencies of $d^{*}(x)$ from e.g. age, tax rate, risk aversion or the ratio $\frac{p}{P}$ can only be derived numerically.

In our numerical analyses, we calculated the critical frailty factors for different ages and tax rates assuming $p=0.25 \cdot P, p=0.5 \cdot P$ and $p=0.75 \cdot P$. In other words, $p=0.25 \cdot P$ means that $25 \%$ of the lump sum benefit $P$ consists of premiums paid and $75 \%$ consists of earnings during the accumulation period. The case $p=P$ would mean that no earnings have occurred in the accumulation period. Critical frailty factors for $p=P$ obviously coincide with the results under the old tax regime.

The critical frailty factors under the old tax regime (without tax incentives for annuitization) are shown in Figure 2 and under the new tax regime (with tax incentives for annuitization) for different values of $p$ in Figures 3a-3c.

In all figures, the solid lines show the critical frailty factors for a risk neutral insured and a marginal tax rate of $25 \%, 30 \%, 35 \%, 40 \%$, and $45 \%$, respectively ${ }^{7}$, the dashed lines in the middle show the corresponding values for an insured with moderate risk aversion, the dashed lines on top show the corresponding values for an insured with a strong risk aversion.

A comparison of the critical frailty factors under the new and old tax regime lead to the obvious conclusion that the new tax regime indeed provides a stronger incentive for annuitization: From the results presented in Figures 2 


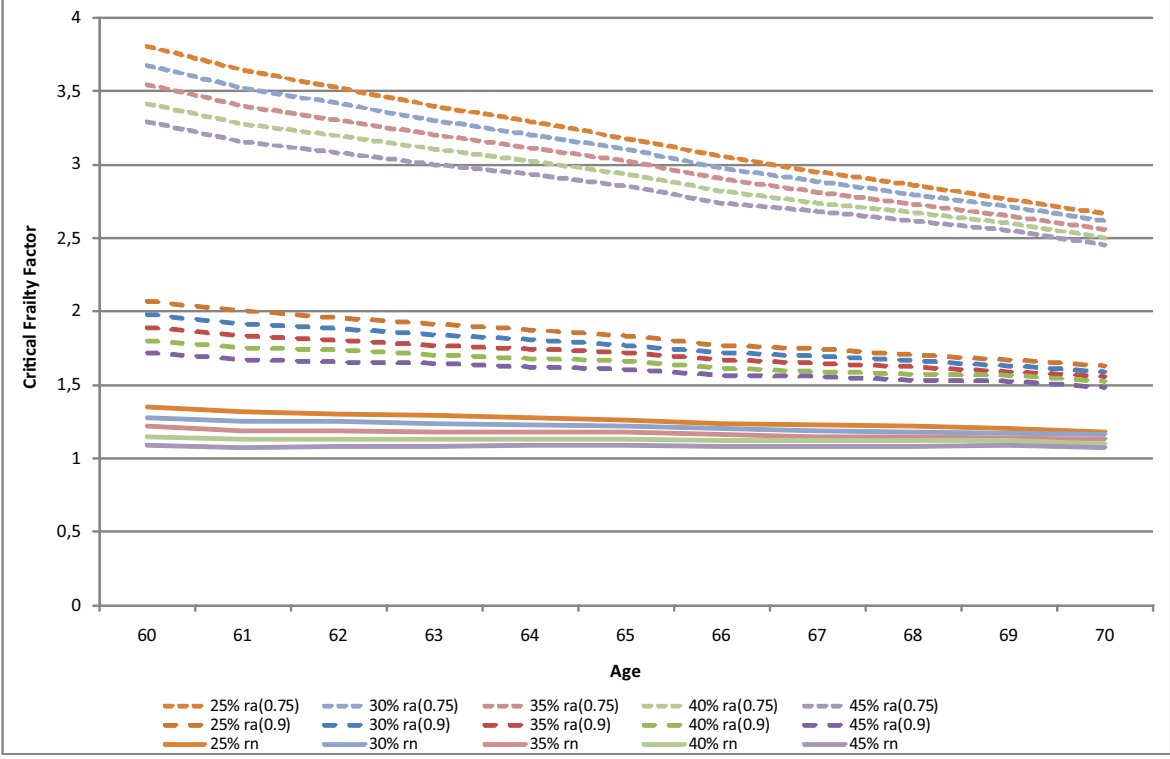

FIGURE 2: Critical frailty factor for different ages and tax rates $(25 \%, 30 \%, 35 \%, 40 \%$, and $45 \%$ top to

bottom in each group of lines) under the old tax regime (solid lines: risk neutral (rn); lower dashed lines: moderately risk averse $(\mathrm{ra}(0.9))$; upper dashed lines: strongly risk averse $(\mathrm{ra}(0.75)))$ assuming an interest rate of $r=4 \%$. (Color online)

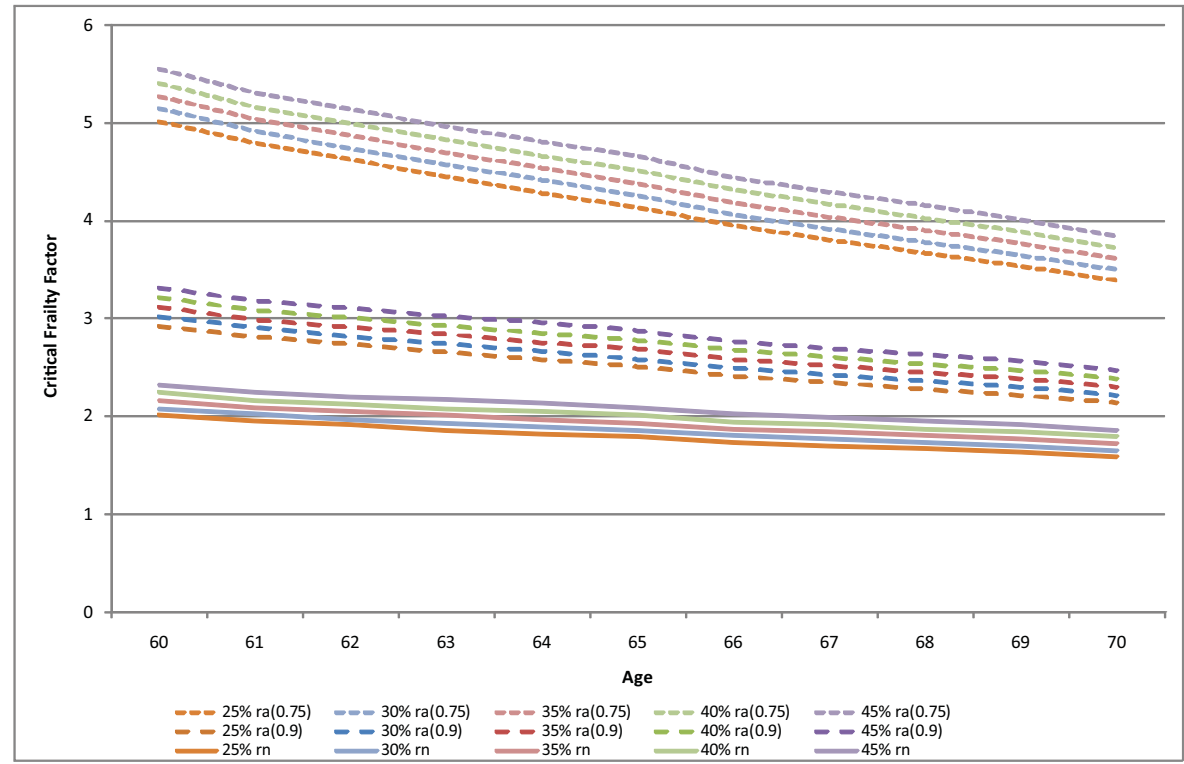

FIGURE 3a: Critical frailty factor for different ages and tax rates $(25 \%, 30 \%, 35 \%, 40 \%$, and $45 \%$ bottom to top in each group of lines) under the new tax regime for $p=0.25 \cdot P$ (solid lines: risk neutral (rn); lower dashed lines: moderately risk averse $(\mathrm{ra}(0.9))$; upper dashed lines: strongly risk averse $(\mathrm{ra}(0.75)))$ assuming an interest rate of $\mathrm{r}=4 \%$. (Color online) 


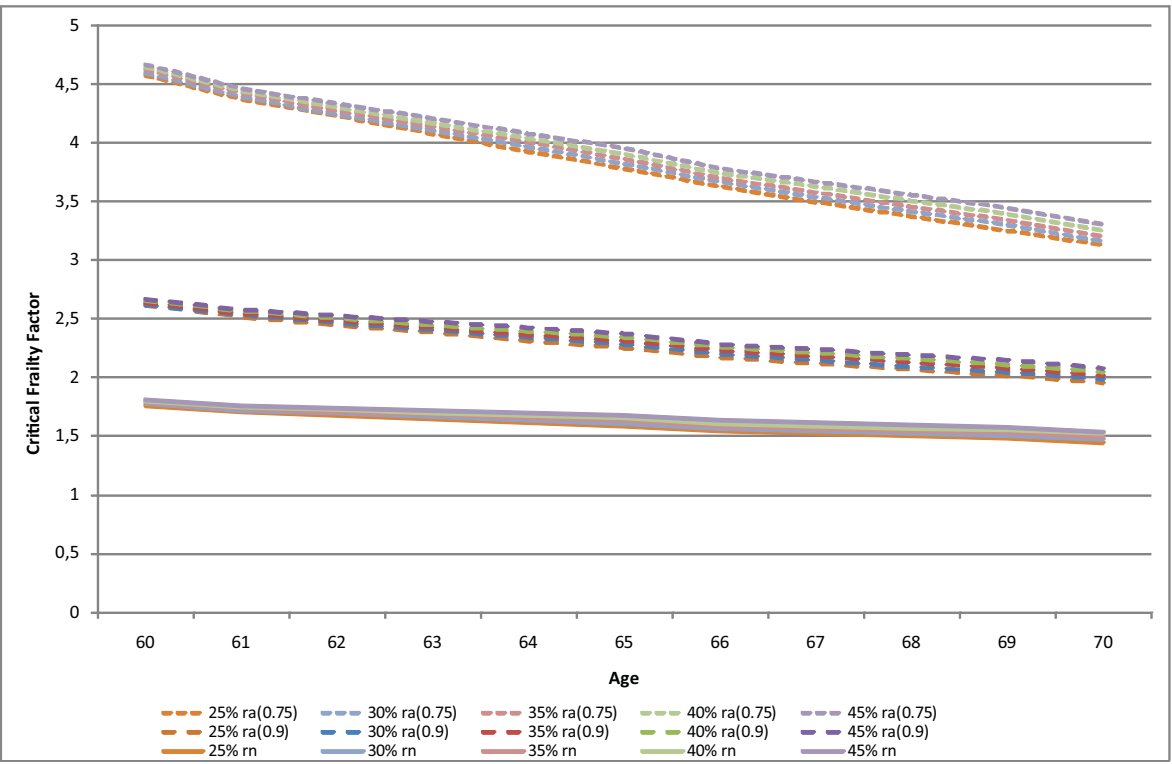

FIGURE 3b: Critical frailty factor for different ages and tax rates $(25 \%, 30 \%, 35 \%, 40 \%$, and $45 \%$ bottom to top in each group of lines) under the new tax regime for $p=0.5 \cdot P$ (solid lines: risk neutral (rn); lower dashed lines: moderately risk averse $(\mathrm{ra}(0.9))$; upper dashed lines: strongly risk averse $(\mathrm{ra}(0.75)))$ assuming an interest rate of $r=4 \%$. (Color online)

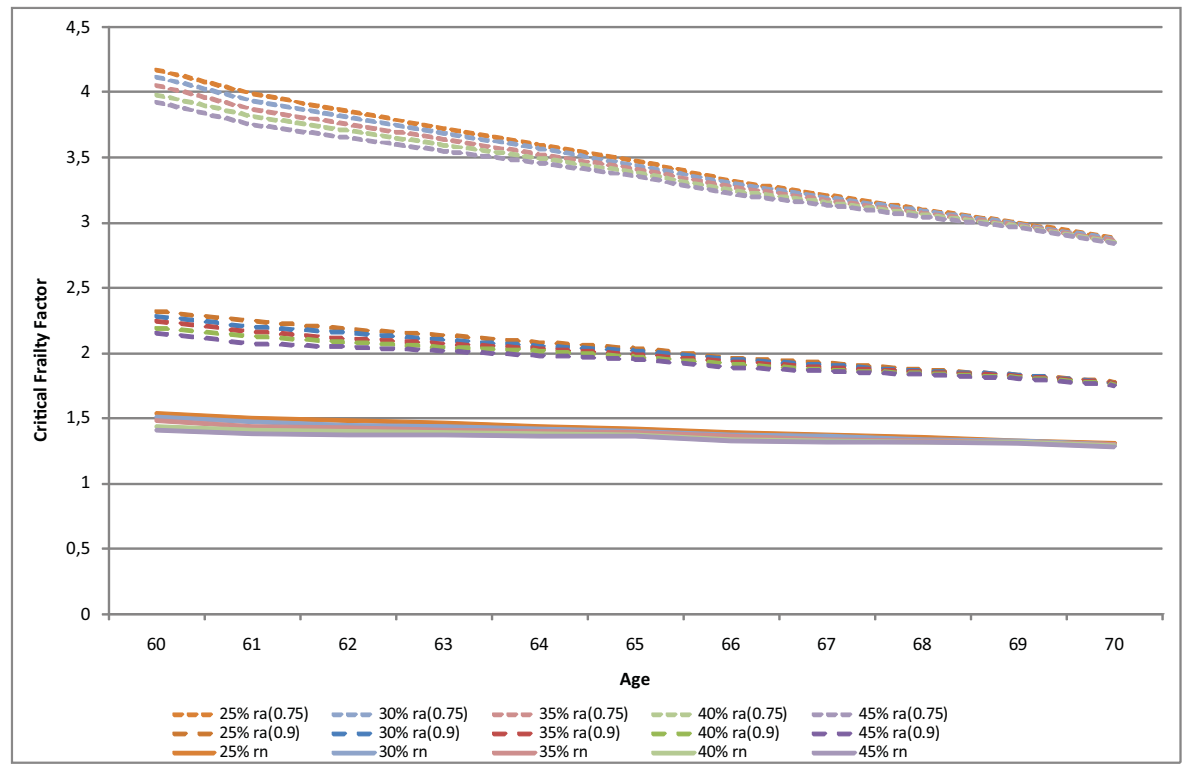

FIGURE 3c: Critical frailty factor for different ages and tax rates $(25 \%, 30 \%, 35 \%, 40 \%$, and $45 \%$ top to bottom in each group of lines) under the new tax regime for $p=0.75 \cdot P$ (solid lines: risk neutral (rn); lower dashed lines: moderately risk averse $(\mathrm{ra}(0.9))$; upper dashed lines: strongly risk averse $(\mathrm{ra}(0.75)))$ assuming an interest rate of $r=4 \%$. (Color online) 
and $3 a-3 c$, we see that, under the new tax regime, the critical frailty factors are higher than in the old tax regime, and thus more people should annuitize.

The incentive for annuitization under the new tax regime increases with increasing earnings in the accumulation phase (i.e. with decreasing $p$ ). Again, this is not surprising: If the money is not annuitized, $50 \%$ of capital gains from the savings period are subject to taxation. Therefore, the benefit of annuitization (and hence critical frailty factors) increases as these gains increase (i.e. as $p$ decreases), all other things equal. Under the new tax regime and for lower values of $p$, the annuity would even be attractive for individuals in a rather bad state of health. For instance for $p=0.25$ (Figure 3a) and a strongly risk averse 60 year old, critical frailty factors are above 5 for all tax rates, meaning that annuitization is preferable even if an individual's mortality rates are five times average rates. Under the old tax regime, the corresponding critical frailty factors (Figure 2) were between 3.3 and 3.8 (depending on the tax rate).

Still, it is worthwhile noting that even under the conditions of the former tax regime, most values for risk neutral customers exceed one, which basically reflects the fact that the taxable portions (given in Appendix A) underestimate the earnings in the annuity payout phase ${ }^{8}$ and therefore already provide some incentive for annuitization (see also Charupat and Milevsky, 2001; Richter and $\mathrm{Ru}, 2002$ who come to similar findings for the situation in Canada). If taxable portions were "fair" in the sense that exactly the earnings of the annuity were taxed for an average individual (i.e. an individual with frailty factor 1), then the solid line in Figure 2 for a tax rate of $25 \%$ would be flat at 1, since an individual with $d=1$ and a tax rate of $25 \%$ would be indifferent between annuitizing or taking the lump sum (due to the relation $r^{*}=0.75 \cdot r$ ). The fact that this line in Figure 2 is decreasing in age means that the incentive resulting from the definition of the taxable portions is decreasing in age.

Another quite obvious result is the fact that critical frailty factors, independent of the tax regime and premium portion $p$, are increasing with the level of risk aversion. In all figures shown, the critical frailty factors are always the lowest for risk neutral individuals (solid lines). Further, critical frailty factors for strongly risk averse individuals are always almost twice as high as for moderately risk averse individuals. As the annuity hedges individual longevity risk, risk aversion obviously strengthens the incentive to annuitize.

Under both tax regimes, critical frailty factors are decreasing in age. Under the old tax regime, e.g., a 60-year old male with moderate risk aversion and a tax rate of $30 \%$ should annuitize if his individual frailty factor is below 1.98 . At the age of 70 , the critical frailty factor is only 1.59 . There are two reasons for this effect. First, taxable portions underestimate the expected earnings in the annuity phase. Since these earnings are lower for higher ages (due to a shorter life expectancy), this advantage of annuities is decreasing in age. Second, the impact of a given frailty factor is higher for higher ages, since it is applied multiplicatively to higher base mortality rates.

Having a closer look on the effect of the tax rate on critical frailty factors, different conclusions can be drawn. Under the old tax regime, consistent with 
our assumption of a flat tax rate being applied to capital gains outside the insurance contract, the benefit of annuitization decreases with increasing individual tax rate (which is applied to the annuity's taxable portion). This is as expected since the value of the annuity decreases in the tax rate whereas the value of the lump sum is independent of the tax rate.

Under the new tax regime, however, we find a somewhat surprising effect: Critical frailty factors are increasing in the tax rate for rather low values of $p$ (i.e. high gains in the accumulation phase) and decreasing in the tax rate for rather high values of $p$ (i.e. low gains in the accumulation phase). This is due to two superimposing effects: On one hand, taxes have to be paid on the gains from the accumulation phase if the lump sum is taken. This effect makes the lump sum less valuable as the tax rate increases. On the other hand, the taxable portion of the annuity also has to be taxed at the insured's individual tax rate. This effect makes the annuity less valuable as the tax rate increases. If gains in the accumulation period are high (i.e. for low values of $p$ ), the first effect is dominant. Therefore, with increasing tax rate, the value of the lump sum decreases faster than the value of the annuity which leads to increasing critical frailty factors.

In contrast, if gains in the accumulation period are low (i.e. for high values of $p$ - and thus also for the old tax system that coincides with $p=P$ ), the second effect outweighs the first and critical frailty factors decrease in the tax rate. Therefore, the effect of an increasing tax rate in the former German taxation framework for annuities was unambiguous. As a lump sum benefit was (under the required conditions) not taxed at all, the ceteris paribus decreasing value of the annuity would lead to a decrease in the critical frailty factor with increasing tax rate. Stronger taxation thus, would set disincentives for annuitization.

Finally, we analyzed the impact of the interest rate $r$ on our results (always assuming $\left.r^{*}=0.75 \cdot r\right)$. We have calculated all values displayed in Figures 2, $3 \mathrm{a}-3 \mathrm{c}$ also for values of $r=2 \%$ and $r=6 \%$, respectively and found a somewhat interesting effect: The relation between the 15 different lines in each figure remained rather stable under all interest rate scenarios. However, critical frailty factors were significantly increasing in $r$. Figure 4 displays the results under the old tax regime for $r=2 \%$. When comparing Figures 2 and 4 , we find that all critical frailty factors in Figure 4 are significantly lower. This effect results from the fact that the taxable portions given in the German income tax law, do not change when interest rates change. As explained in Section 1, these taxable portions are meant to approximate the insured's earnings in the annuity payout phase assuming some fixed rate of interest is credited to the contract. Obviously, when actual interest rates are very low, this approximation overestimates the "correct" earnings and hence too much taxes are paid. Hence, the attractiveness of annuities decreases and critical frailty factors decrease accordingly.

Summarizing, the results presented so far at first glance suggest that tax incentives for annuitization do work since they make annuitization the preferable choice for a larger group of people. However, the analyses in the next Section will show that this comes at a price: The heterogeneity of the value for money also increases, leading to significant redistribution effects. These distribution effects 


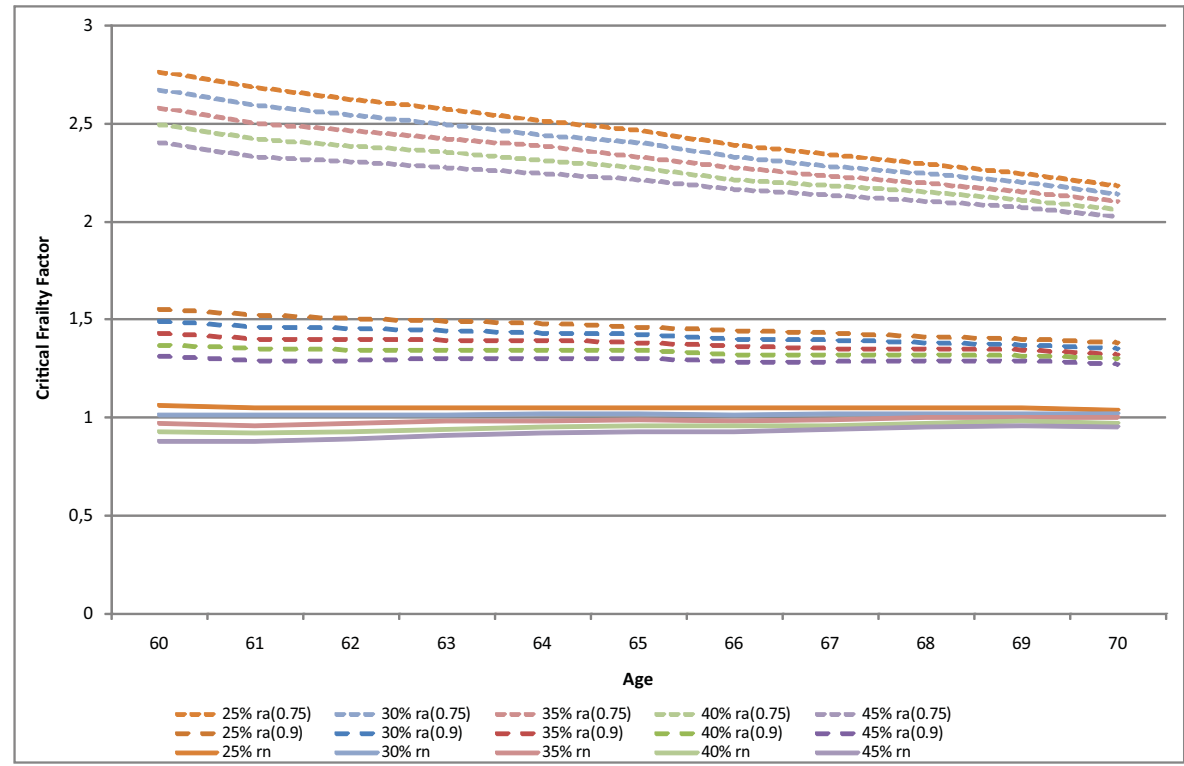

FIGURE 4: Critical frailty factor for different ages and tax rates $(25 \%, 30 \%, 35 \%, 40 \%$, and $45 \%$ top to bottom in each group of lines) under the old tax regime (solid lines: risk neutral (rn); lower dashed lines: moderately risk averse (ra(0.9)); upper dashed lines: strongly risk averse $(\mathrm{ra}(0.75)))$ assuming an interest rate of $r=2 \%$. (Color online)

are somewhat similar to results found by Gong and Webb (2008) for the case of mandatory annuitization.

\section{ANALYSES FOR A POOL OF INSURED}

In this Section, we analyze the effect of tax incentives for annuitization on an insurer in a market without enhanced annuities. For this purpose, we model a heterogeneous pool of individuals. As described in Section 2, we assume the frailty factor $d$ in the general population to follow a Gamma distribution. We assume that everybody with a frailty factor below the critical factor annuitizes and everybody else does not. Of course this is somewhat oversimplifying: First, the decision of whether or not to annuitize may also depend on other criteria than the expected value of the annuity. For instance some insured might simply need the money at the end of the accumulation phase to pay off a mortgage, etc. This would have the effect that this group of insured would never annuitize and the results of our analyses would apply for the remaining group only. Second, although it is true that most insured do have information about their state of health and would not annuitize if they are rather impaired, it is of course unrealistic to assume that all insured know their exact frailty factor. Therefore, in reality there would rather be an annuitization probability that decreases as 
TABLE 1

PERCENTAGE AND AVERAGE FRAILTY FACTORS OF INSURED WHO ANNUITIZE FOR A POOL OF INDIVIDUALS UNDER THE OLD TAX REGIME.

\begin{tabular}{lcc}
\hline \hline & Percentage of Insured who Annuitize & Average $d$ \\
\hline Tax rate $25 \%$ & $80.46 \%$ & 0.86 \\
Tax rate $35 \%$ & $75.30 \%$ & 0.84 \\
Tax rate $45 \%$ & $67.92 \%$ & 0.81 \\
\hline \hline
\end{tabular}

frailty increases but not a "sharp" cutoff between annuitization probability 1 up to the critical frailty factor and 0 above that level.

In the following numerical analyses, we consider a pool of 65 year old male, risk neutral annuitants with different tax rates and assume $P=100,000.00 €$ and different values for $p$.

We applied Monte Carlo techniques using the random number generator "Mersenne Twister MT19937" and the function "gsl_ran_gamma" of the library "GNU Scientific Library Version 1.8"9 to "create" 10,000 individuals by drawing their frailty factor from the gamma-distribution introduced in Section 2. Where correlated gamma-distributed random variables are required, we use a Gaussian copula and choose the correlation parameter in the copula such that the linear correlation between the gamma-distributed random variables achieves the desired value.

Whenever a person's frailty factor is below the critical frailty factor, we assume that the person would annuitize in the standard annuity contract introduced in Section 2. Otherwise, we assume that the person would prefer the lump sum benefit. From this, we can calculate the percentage of insured who do annuitize and the average frailty factor of those who annuitize. Table 1 gives the results under the old tax regime.

Under the new tax regime, we calculate the same values and also look at the effect of the tax change on the insurer's profitability due to the fact that - if tax incentives are present - individuals with reduced life expectancy annuitize for tax reasons. In the last column of the following table, we therefore give the increase in percentage points of the insurer's profitability rate (which is defined as the money annuitized minus the present value of all the annuities paid out as a percentage of the money annuitized).

Table 2 gives the corresponding results under the new tax regime.

First it is worth noting that the tax incentives work as intended in the sense that the percentage of people who annuitize increases significantly. For instance, with a tax rate of $45 \%$, under the old tax regime only $67 \%$ of the insured should annuitize. Under the new tax regime this percentage goes up to values between $86 \%$ and $99 \%$ depending on the considered gains from the accumulation phase. Of course it holds independent of the tax rate that, the more people should annuitize the higher these gains which would otherwise be taxed. 
TABLE 2

PERCENTAGE AND AVERAGE FRAILTY FACTORS OF INSURED WHO ANNUITIZE AND INCREASE IN INSURER'S PROFITABILITY FOR A POOL OF INDIVIDUALS UNDER THE NEW TAX REGIME.

\begin{tabular}{llccc}
\hline \hline & & $\begin{array}{l}\text { Percentage of } \\
\text { Insured who } \\
\text { Annuitize }\end{array}$ & Average $d$ & $\begin{array}{c}\text { Increase in Insurer's } \\
\text { Profitability Rate }\end{array}$ \\
\hline Tax rate 25\% & $p=0.25 \cdot P$ & $96.08 \%$ & 0.96 & $1.98 \%$ \\
& $p=0.5 \cdot P$ & $92.77 \%$ & 0.94 & $1.49 \%$ \\
Tax rate 35\% & $p=0.75 \cdot P$ & $87.85 \%$ & 0.90 & $0.86 \%$ \\
& $p=0.25 \cdot P$ & $97.64 \%$ & 0.98 & $2.79 \%$ \\
Tax rate 45\% & $p=0.5 \cdot P$ & $93.83 \%$ & 0.94 & $2.20 \%$ \\
& $p=0.75 \cdot P$ & $86.83 \%$ & 0.90 & $1.29 \%$ \\
& $p=0.25 \cdot P$ & $98.71 \%$ & 0.99 & $3.76 \%$ \\
& $p=0.5 \cdot P$ & $94.55 \%$ & 0.95 & $3.09 \%$ \\
\hline \hline & $p=0.75 \cdot P$ & $85.54 \%$ & 0.89 & $1.92 \%$ \\
\hline
\end{tabular}

However, it has to be added that the percentage of the insured who should annuitize in our model is significantly higher than experienced in most insurance markets. This might be due to the fact that insurers anticipate adverse selection in premiums, and also include loadings reflecting other expenses, which would make "real" products less attractive than our generic product.

In the old tax framework, the average $d$ is significantly below 1 , reflecting the well-established problem of adverse selection: If only standard annuities are offered, insurance is particularly attractive for high risk individuals (in our case the ones in very good health) and would not be purchased by individuals in very poor health which decreases the average frailty factor in the portfolio of annuitized risks.

An immediate consequence of the higher annuitization rates resulting from the tax change is that the pool of insured becomes "more impaired", i.e. the average frailty factor in the pool of annuitants significantly increases. In other words, the insurer has more low risk types in its insured portfolio. So the considered tax incentives not only work in the sense that they increase the portion of people who annuitize, it also has the positive effect of decreasing adverse selection effects. This has a positive impact on the insurer's profitability as can be seen from the last column of Table 2. On the other hand, however, this means that, all other things equal, a portion of the tax incentives that were intended to go to the insured actually goes to the insurer in the form of an increased profit. (In a competitive market, of course, this advantage would be passed on to the insured in some way, which implies there is a secondary effect induced by the taxes, ultimately further increasing demand, cf. also Section 6).

Although we have seen that tax incentives are an effective means to significantly increase the portion of individuals for which annuitization is preferable and to reduce the negative effects of adverse selection on the insurer's profitability, tax incentives can not solve the problem that different individuals receive a 
different value for money out of annuitizing. For instance, under the new tax regime and in the case $p=0.25 \cdot P$, a 65 year old with a tax rate of $30 \%$ should annuitize if the frailty factor is below 1.86. An individual with a frailty factor of 1.86 would of course get a significantly lower expected present value of the annuity stream for the same money annuitized than an individual with a frailty factor of, say, 0.8. So tax incentives yield the unintended side effect of stimulating demand for products that are "priced too high" for many of the individuals ultimately purchasing them. A product with a low value for money can turn out to be the best choice only because alternative products come with a higher tax burden. This is undesired insofar, as healthy individuals profit from both, the high value for money of the product (resulting from their good state of health) and the tax benefits whilst for impaired individuals a significant portion of the tax benefit is needed to compensate for the poor value for money of the product.

We now analyze this heterogeneity in the population with respect to value for money of annuitization: For each individual, we calculate the present value of the expected annuity cash-flow after taxes taking into account their individual mortality probabilities. From this, we derive the following "heterogeneity coefficient" which provides a measure for the heterogeneity in value for money: The $95^{\text {th }}$ percentile of this present value divided by its $5^{\text {th }}$ percentile. In our model of a market without enhanced annuities, this value is 1.31 , meaning that the present value of the expected annuity cash-flow for a healthy individual (represented by the $95^{\text {th }}$ percentile of this present value and thus by the $5^{\text {th }}$ percentile of the frailty factor $d$ ) exceeds the corresponding value for a rather impaired individual (represented by the $95^{\text {th }}$ percentile of the frailty factor) by $31 \%$.

In the following Section, we analyze how the heterogeneity changes if enhanced annuities are introduced to the market.

\section{INTRODUCING ENHANCED ANNUITIES}

In this Section, we analyze how the effects observed above change in a market where enhanced annuities are offered.

Of course, in the theoretical case of perfect underwriting when the result of the underwriting $\hat{d}$ (i.e. the estimate for the actual frailty factor $d$ ) coincides with the actual frailty factor, basically everybody would get the same value for money when annuitizing. If underwriting is less than perfect, i.e. $\rho_{\hat{D}, D}<1$, there will be some insured for which the underwriting underestimates their frailty factor and others for which the underwriting overestimates their frailty factor. This creates heterogeneity with respect to the value for money.

We now assume that each insured is offered an annuity based on the insurer's underwriting, i.e. an annuity that is calculated with the estimated frailty factor $\hat{d}$ as described in Section 2 .

As in the previous section we only consider the case of a risk neutral insured, i.e. we assume that the insured does annuitize if the present value of the expected annuity cash-flow after taxes exceeds the lump sum benefit after taxes. 
PERCENTAGE AND AVERAGE FRAILTY FACTORS OF INSURED WHO ANNUITIZE FOR A POOL OF INDIVIDUALS IN THE PRESENCE OF ENHANCED ANNUITIES FOR CORRELATION 1 (PERFECT UNDERWRITING).

\begin{tabular}{llrr}
\hline \hline & & $\begin{array}{c}\text { Percentage of Insured } \\
\text { who Annuitize }\end{array}$ & Average $d$ \\
\hline Old tax regime & Tax rate $\mathbf{2 5} \%$ & $100.00 \%$ & 1.00 \\
& Tax rate $\mathbf{3 5} \%$ & $100.00 \%$ & 1.00 \\
& Tax rate $\mathbf{4 5} \%$ & $98.93 \%$ & 0.99 \\
New tax regime & Any combination of & $100.00 \%$ & 1.00 \\
& $p=0.25 \cdot P, p=0.5 \cdot P$, & & \\
& $p=0.75 \cdot P$ & & \\
& and tax rate $\mathbf{2 5} \% \mathbf{3 5} \% \mathbf{~ o r ~} \mathbf{4 5} \%$. & \\
\hline
\end{tabular}

In Tables 3 and 4 , we see how the results from the previous section change in a market with enhanced annuities assuming $\rho_{\hat{D}, D}=1$, and $\rho_{\hat{D}, D}=0.75$, respectively.

We start with the result in the hypothetical case of perfect underwriting, i.e. $\rho_{\hat{D}, D}=1$. The results for the old and new tax regime, are given in Table 3 .

We can see that in the case of perfect underwriting, everybody should annuitize (except for the extreme case of the maximum tax rate combined with the old tax regime, where still just the unhealthiest $1 \%$ of the population would do better with a lump sum). So we can conclude that introducing enhanced annuities with good quality of underwriting is a more efficient means to increase the portion of individuals who annuitize than tax incentives. We can also see that introducing enhanced annuities still has an additional positive effect in an economy with tax incentives for annuitization. Since everybody annuitizes, obviously the average frailty factor in the portfolio is 1 and there is no adverse selection.

Finally, since the pricing of the annuity perfectly reflects the individual's state of health, all consumers receive essentially the same (expected) value for money. As a result, the heterogeneity coefficient drops to $1.03 .^{10}$

We can conclude that in the case of perfect underwriting, enhanced annuities are a very effective means in increasing the share of people who should annuitize, doing away with adverse selection and making sure that everybody gets essentially the same value for money.

We will now consider the case where underwriting is less than perfect by assuming that the correlation between the estimated and the actual frailty factor is below 1 . Table 4 shows the corresponding results for a correlation of 0.75 .

If the underwriting is not perfect, there will be some insured where the estimated frailty factor is significantly lower than the actual frailty factor. In our model, these insured would not annuitize. Therefore, less than $100 \%$ of the individuals annuitize but still significantly more than in a market without enhanced annuities.

Of course, the imperfection of the underwriting could also go the other way, resulting in some rather healthy persons being underwritten as impaired. In that 
TABLE 4

PERCENTAGE AND AVERAGE FRAILTY FACTORS OF INSURED WHO ANNUITIZE FOR A POOL OF INDIVIDUALS IN THE PRESENCE OF ENHANCED ANNUITIES FOR CORRELATION 0.75 .

\begin{tabular}{lllcc}
\hline \hline & & $\begin{array}{c}\text { Percentage of Insured } \\
\text { who Annuitize }\end{array}$ & Average $d$ \\
\hline Old tax regime & Tax rate 25\% & & $86.47 \%$ & 0.94 \\
& Tax rate 35\% & & $78.71 \%$ & 0.92 \\
& Tax rate 45\% & & $68.55 \%$ & 0.89 \\
New tax regime & Tax rate 25\% & $p=0.25 \cdot P$ & $99.34 \%$ & 1.00 \\
& & $p=0.5 \cdot P$ & $97.94 \%$ & 0.99 \\
& & $p=0.75 \cdot P$ & $94.45 \%$ & 0.97 \\
& Tax rate 35\% & $p=0.25 \cdot P$ & $99.76 \%$ & 1.00 \\
& & $p=0.5 \cdot P$ & $98.47 \%$ & 0.99 \\
& Tax rate 45\% & $p=0.75 \cdot P$ & $93.46 \%$ & 0.96 \\
& $p=0.25 \cdot P$ & $99.91 \%$ & 1.00 \\
& $p=0.5 \cdot P$ & $98.83 \%$ & 0.99 \\
& $p=0.75 \cdot P$ & $91.89 \%$ & 0.96 \\
\hline \hline
\end{tabular}

(small) segment, adverse selection effects could even be worse than in a market without enhanced annuities. Therefore, while introducing enhanced annuities with less than perfect quality of underwriting does still reduce adverse selection effects overall, the effect is smaller than in the case of perfect underwriting. For the same reason, the heterogeneity coefficient increases and amounts to 1.24. In other words, the difference in value for money within the population is larger than in the case with perfect underwriting but still smaller than in a market without enhanced annuities (where it amounts to 1.31).

We also performed analyses for lower correlations: It is worth noting, that under both tax regimes even for a rather low correlation of 0.5 , the percentage of insured that annuitize is at a similar level as in a market where only standard annuities are offered. So, although introducing enhanced annuities with rather poor underwriting quality cannot increase the share of people who annuitize, the average frailty factor of those who do annuitize is significantly higher if enhanced annuities are present meaning that a significant share of impaired people annuitizes in this case. Of course these are the impaired that are correctly underwritten as being impaired or where the impairment is even overestimated. So even if the overall percentage of individuals who do annuitize will not increase if the quality of the underwriting is rather poor, we still have the positive side effect that at least a portion of those who would get a very bad value for money from a standard annuity would now get a fair product. This can also be seen in the heterogeneity coefficient being (slightly) lower than without enhanced annuities.

Finally, we would like to state that as expected in the extreme case of $\rho_{D, \hat{D}}=$ 0 , where underwriting results fluctuate independent of the actual frailty factor, both, selection effects and heterogeneity do increase: The heterogeneity coefficient amounts to 1.44 . 
To summarize, introducing enhanced annuities can decrease selection effects, increase the amount of people who annuitize and decrease heterogeneity in value for money, if the quality of the underwriting is good. In particular, the introduction of these products is more effective than introducing tax incentives. Even for a mediocre quality of the underwriting, positive effects can be observed. Only if the quality of the underwriting is rather poor, introducing enhanced annuities will not succeed in increasing the share of individuals who do annuitize.

\section{CONCLUDING REMARKS}

In this paper, employing a simple frailty model for the individual mortality, we have analyzed the effects of introducing tax incentives for annuitization or enhanced annuities on an individual's decision to annuitize and on the insurer's profitability.

We found that the critical frailty factor below which annuitization is preferable, increases significantly if, all other things equal, tax incentives for annuitization are introduced. In other words, in the presence of tax incentives, annuitization may be preferable even if the insured is rather impaired. It has also been shown how risk aversion increases this effect (note that in this work risk aversion was modeled in a rather simplistic fashion as the insured's tendency to annuitize even at a specified value of money's worth below one).

The interaction, however, between the tax rate and the critical frailty factor within the new framework is ambiguous. On the margin, taxation actually might set disincentives for annuitization, when the share of accumulated gains is rather low such that additional taxation affects the annuity more strongly than the lump sum, resulting in a decrease in the critical frailty factor. With a high proportion of gains, though, annuitization becomes more attractive.

When analyzing a pool of insured, we found that introducing tax incentives for annuitization will indeed as intended increase the portion of individuals who should annuitize. It will also significantly reduce adverse selection. However, the problem that different insured receive a different value for money is even increased by tax incentives which indicates that this approach to incentivizing annuitization needs to be used very carefully as it leads to significant crosssubsidization towards the healthy at the cost of insured in bad health.

Given these concerns, this paper addressed another approach that might improve the market share of annuities: enhanced annuities. It was shown, that if enhanced annuities are available - either instead or on top of tax incentives in the case of good quality of underwriting, all three targets are reached simultaneously: The portion of individuals who should annuitize increases dramatically, adverse selection is eliminated and essentially all insured receive the same value for money.

If, however, the quality of underwriting is rather poor, the portion of individuals who should annuitize does not increase. However, adverse selection is still reduced. The heterogeneity of the value for money increases with decreasing 
quality of underwriting, reaching the level of the case without enhanced annuities at a correlation of slightly below 0.5 .

These results have straightforward policy implications. While recent developments, e.g. in Germany seem to indicate that a tendency exists towards mandatory annuitization in some segments and tax incentives in others, our analysis suggests that there are other potentially more efficient ways of addressing the issue with less severe market intervention. In a market where annuitization is mandatory, but without risk-adequate annuitization, it needs to be analyzed carefully how this strong intervention is justified. Even if there is a welfare gain, e.g. from reduced reliance on the state respectively social security, adverse effects must not be overlooked. Obviously, mandatory annuitization in such an environment creates a clear externality which favors those in good health, as they would be subsidized by the others. The resulting welfare effects need to be kept in mind.

On the other hand, creating a framework that incentivizes or obligates annuity providers to offer enhanced annuities would provide equal or similar money's worth to all annuitants. Also our results suggest that, if done correctly, such a policy would increase the popularity of annuitization without favoring one group at the cost of the other. So, under these circumstances, it might not even be necessary to make annuitization mandatory. On the other hand, however, if annuitization is mandatory, there should also be a requirement that annuities are provided in a risk-adequate manner, or in other words, that enhanced annuities are offered.

The intention of this analysis was to derive the key results in a rather simple and intuitive model. Therefore, there is a wide range of possible extensions to our model for future research. For instance, we have neglected charges and expenses and have used a rather simplistic approach towards modeling risk aversion. Furthermore, we have not considered the "feedback" effect between changes in adverse selection and annuity prices. In reality, insurers would react to stronger adverse selection (i.e. higher values of $\mathrm{d}^{*}$ ) by increasing prices (i.e. decreasing annuity payouts) and vice versa. However, considering this feedback effect and calculating corresponding theoretical equilibrium prices would even increase the observed effects: As we have seen in our analyses, introducing tax incentives or enhanced annuities to a market c.p. reduces selection effects and therefore increases the insurer's profit. The insurer would react by reducing the prices of annuities (i.e. annuity payouts would go up). This effect would further increase demand leading to another increase in insurer's profit to which the insurer would again react by reducing prices and so on, until some kind of equilibrium is reached. Analogously, abolishing tax incentives or enhanced annuities in a market would c.p. decrease the insurer's profit leading to an increase in annuity prices which further reduces demand, etc. Under certain circumstances this could even lead to a collapsing market in the spirit of Akerlof (1970), i.e. demand would drop to essentially zero. 


\section{NOTES}

1. To be more precise: It is assumed that an individual (of either gender) of age $\mathrm{x}$ lives exactly to the remaining life expectancy for a male person aged $\mathrm{x}$. Then, an amount of the annuity paid up to this life expectancy is calculated, such that the present value of this annuity (using a discount rate of $3 \%$ ) equals 1 . For a 65 year old, e.g., the sum of the annuities received is 1.22 . Hence $82 \%$ of the annuities received is the money invested in the annuity $(82 \% * 1,22=1)$ and $18 \%$ of the annuities received is considered interest. Thus, the taxable portion for annuities starting at age 65 is set to $18 \%$. Due to the skewed distribution of the remaining lifetime around its expectation and due to differences between actual interest rates earned and the assumed $3 \%$, this is merely an approximation for the expected earnings of an annuity.

2. In substandard annuities, contrasting standard annuities, the annual payment depends on the insured's health status. Enhanced annuities and impaired annuities can be considered subcategories of substandard annuities. These two terms are sometimes used synonymously, but more detailed definitions characterize enhanced annuities as offering modest increases in the annuity payments, underwritten based upon lifestyle factors and medical conditions, while impaired annuities would be underwritten based upon serious health impairments such as stroke, heart attack etc. While enhanced annuities can be underwritten using automated underwriting systems, impaired annuities require individual assessment (see, e.g. Weinert (2006), Gatzert et al. (2009) or Richards and Jones (2004). For the sake of our analyses, it is not necessary to distinguish between the terms substandard annuities, enhanced annuities and impaired annuities.

3. Of course, this is simplifying. Besides impairments that result in a rather constant frailty factor, there are impairments that result in a higher mortality for a certain number of years only. If this period is survived, mortality is "back to normal". For other impairments, excess mortality (i.e. the difference between individual mortality rates and average mortality rates) might decrease gradually. See, e.g. Carver (2009) for some examples. While it is essential to consider such effects when performing actual underwriting, it can be neglected in the analysis of the general effects of enhanced annuities on an insurance market.

4. Of course, since the life expectancy or the present value of an annuity are not linear in $d$, $\mathrm{E}(d)=1$ does not imply, that the average life expectancy (or the average present value of an annuity) in a population coincides with the life expectancy of (or present value of an annuity for) an individual with $d=1$.

5. In practice, there might be a bias due to imperfect underwriting, e.g. an unconscious underestimation of frailty factors because the underwriter is aware of adverse selection. The model could be adjusted to allow for $D$ and $\hat{D}$ having different distributions.

6. For $\hat{d}<1$, we substitute $\hat{d} \cdot q_{\omega}$ by 1 , where $\omega$ denotes the so-called limiting age of the standard mortality table, i.e. the age that, according to that table, will not be exceeded. Thus, any remaining probability mass is assigned to the mortality rate of the last year. Also, for $\hat{d}>1$, we have to substitute $\hat{d} \cdot q_{x}$ by 1 whenever $\hat{d} \cdot q_{x}>1$.

7. The marginal tax rate currently is 0 up to an annual income of 8,004 EUR. It then grows from $14 \%$ to $42 \%$ which is reached for an income of 52,882 EUR. For any income beyond 250,731 EUR, a marginal tax rate of $45 \%$ is applied.

8. This primarily results from the rather low assumed rate of interest of $3 \%$ when taxable portions were derived, cf. Section 1.

9. Cf. http://www.gnu.org/software/gsl.

10. One might expect a value of 1.00 . The deviation simply results from the fact that we assume $\mathrm{r}^{*}<\mathrm{r}$.

\section{REFERENCES}

AKERLOF, GEORGE A. (1970) The market for 'Lemons': Quality uncertainty and the market mechanism. The Quarterly Journal of Economics, 84, 488-500.

BERNHEIM, B. D. (1991) How strong are bequest motives? Evidence based on estimates of the demand for life insurance and annuities. Journal of Political Economy 99, 899-927. 
CARVer, L. (2009) An unhealthy interest. Life \& Pensions December 2009, 19-22.

Charupat, N. and MilevSKy, M.A. (2001) Mortality swaps and tax arbitrage in the Canadian insurance and annuity market. The Journal of Risk and Insurance 68, 277-302.

Finkelstein, A. and Poterba, J. (2004) Adverse selection in insurance markets: Policyholder evidence from the UK annuity market. Journal of Political Economy 112, 183-208.

Gatzert, N., Hoer manN, G. and Schmeiser, H. (2009) Optimal rate classification and underwriting risk for substandard annuities. Zeitschrift für die gesamte Versicherungswissenschaft 98(5), 565-577.

GoNG, G. and WeBB, A. (2008) Mortality heterogeneity and the distributional consequences of mandatory annuitization. Journal of Risk and Insurance 75, 1055-1079.

HoERMANN, G. and RUß, J. (2008) Enhanced annuities, individual underwriting and adverse selection - A solution for the annuity puzzle? Insurance: Mathematics and Economics 43, 150-157.

James, E. and SonG, X. (2001) Annuities Markets Around the World: Money's Worth and Risk Intermediation, working paper.

KotLIKOFF, L. J. and SPIVAK, A. (1981) The family as an incomplete annuities market. Journal of Political Economy 89, 372-391.

Mitchell, O., Poterba, J. M., Warshawsky, M. J. and Brown, J. R. (1999) New evidence on the money's worth of individual annuities. American Economic Review 89, 1299-1318.

RichARDS, S. and JONES, G. (2004) Financial aspects of longevity risk, Working Paper presented to the Staple Inn Actuarial Society.

RichteR, A. and RUB, J. (2002) Tax arbitrage in the German insurance market. Blätter der $D G V M, \mathbf{X X V}(3), 659-672$.

STRAWCZYNSKI, M. (1999) Income uncertainty and the demand for annuities. Economic Letters 63, 91-96.

Vaupel, J., Manton, K. and Stallard, E. (1979) The impact of heterogeneity in individual frailty on the dynamics of mortality. Demography 16(3), 439-454.

WeInerT, T. (2006): Enhanced Annuities on the Move, in: Hannover Re's Perspectives - Current Topics of International Life Insurance, 13.

ALEXANDER KLING (Corresponding author)

Institut für Finanz- und Aktuarwissenschaften, Ulm, Germany

phone: +4973120644242

E-Mail: a.kling@ifa-ulm.de

ANDREAS RICHTER

Professor, Chair in Risk \& Insurance

Ludwig-Maximilians University Munich, Germany

phone: +498921803755

E-Mail: richter@lmu.de

JOCHEN RUß

Managing Partner

Institut für Finanz- und Aktuarwissenschaften, Ulm, Germany

phone: +4973120644233

E-Mail: j.russ@ifa-ulm.de 
APPENDIX A TABLE OF TAXABLE PORTIONS

\begin{tabular}{lccccc}
\hline \hline $\begin{array}{l}\text { Age at } \\
\text { Annuitization }\end{array}$ & $\begin{array}{c}\text { Taxable } \\
\text { Portion }\end{array}$ & $\begin{array}{c}\text { Age at } \\
\text { Annuitization }\end{array}$ & $\begin{array}{c}\text { Taxable } \\
\text { Portion }\end{array}$ & $\begin{array}{c}\text { Age at } \\
\text { Annuitization }\end{array}$ & $\begin{array}{c}\text { Taxable } \\
\text { Portion }\end{array}$ \\
\hline $0-1$ & $59 \%$ & 38 & $39 \%$ & 64 & $19 \%$ \\
$2-3$ & $58 \%$ & $39-40$ & $38 \%$ & $65-66$ & $18 \%$ \\
$4-5$ & $57 \%$ & 41 & $37 \%$ & 67 & $17 \%$ \\
$6-8$ & $56 \%$ & 42 & $36 \%$ & 68 & $16 \%$ \\
$9-10$ & $55 \%$ & $43-44$ & $35 \%$ & $69-70$ & $15 \%$ \\
$11-12$ & $54 \%$ & 45 & $34 \%$ & 71 & $14 \%$ \\
$13-14$ & $53 \%$ & $46-47$ & $33 \%$ & $72-73$ & $13 \%$ \\
$15-16$ & $52 \%$ & 48 & $32 \%$ & 74 & $12 \%$ \\
$17-18$ & $51 \%$ & 49 & $31 \%$ & 75 & $11 \%$ \\
$19-20$ & $50 \%$ & 50 & $30 \%$ & $76-77$ & $10 \%$ \\
$21-22$ & $49 \%$ & $51-52$ & $29 \%$ & $78-79$ & $9 \%$ \\
$23-24$ & $48 \%$ & 53 & $28 \%$ & 80 & $8 \%$ \\
$25-26$ & $47 \%$ & 54 & $27 \%$ & $81-82$ & $7 \%$ \\
27 & $46 \%$ & $55-56$ & $26 \%$ & $83-84$ & $6 \%$ \\
$28-29$ & $45 \%$ & 57 & $25 \%$ & $85-87$ & $5 \%$ \\
$30-31$ & $44 \%$ & 58 & $24 \%$ & $88-91$ & $4 \%$ \\
32 & $43 \%$ & 59 & $23 \%$ & $83-93$ & $3 \%$ \\
$33-34$ & $42 \%$ & $60-61$ & $22 \%$ & $94-96$ & $2 \%$ \\
35 & $41 \%$ & 62 & $21 \%$ & $a b 97$ & $1 \%$ \\
$36-37$ & $40 \%$ & 63 & $20 \%$ & & \\
\hline \hline
\end{tabular}

